\title{
Effect of Reclaim on California Bearing Ratio of Sandy Soil
}

\author{
Mohammed K. Fakhraldin ${ }^{1}$, Tawfek Sheer Ali ${ }^{2}$, Rasha A. Al-Fatlawy ${ }^{3}$ \\ Dr., Civil Eng. Dept., Faculty of Engineering, Kufa University, Najaf, Iraq ${ }^{1}$ \\ Dr., Structures and Water Resources Dept., Faculty of Engineering, Kufa University, Najaf, Iraq ${ }^{2}$ \\ Assistant Lecturer, Civil Eng. Dept., Faculty of Engineering, Kufa University, Najaf, Iraq ${ }^{3}$
}

\begin{abstract}
Recently, a fast evolution of structures in urban centres attended by a dearth of beneficial areas has pushed the specialists to recover soil properties in order to carry the applied loadings of structures. One of the technology of soil advancement is use of admixtures. In Iraq, the tires Reclaim are produced by Ministry of Industry and Metals with low costs because it is considered as a by-product of tires manufacturing. This paper concerned with investigates the use of Reclaim as additive to soil. The effect of Reclaim on California Bearing Ratio (CBR) of sandy soil is studied. Many of laboratory tests was carried out on the original soil ( $0 \%$ Reclaim) and using $0.5 \%, 2 \%, 4 \%$ Reclaim by the weight of soil. A CBR laboratory tests on soil samples without and with Reclaim under 4 days soaking condition to simulate the long-term soaking case. The results show that the dry unit weight of sandy soil increase when the Percent of Reclaim increase. Also, for all cases $(0 \%, 0.5 \%, 2 \%$ and $4 \%)$ Reclaim, CBR increase as the dry unit weight increase for each case. The main important conclusion conducted that CBR decrease when the percent of Reclaim increase, thus, use of Reclaim do not improve the soil to carry the applied loads, the increment in CBR varies from 7.6\% to $68.8 \%$.
\end{abstract}

Keywords: Improvement soil, CBR, Rclaim, Tires waste.

\section{INTRODUCTION}

Recently, a fast evolution of structures in urban centres attended by a dearth of beneficial areas, has pushed the specialists to recover soil properties in order to carry the applied loadings of structures. The technology of ground recovery might be removal and replacement, precompression, vertical drains, in-situ densification, grouting, stabilization using admixtures and reinforcement. The quantity of the old tires dump is increasing as the size of urbanization grows around the world. One of the available options to get rid of these waste products is to recycle them by using them as a stabilizing material. Recently many studies have been conducted to examine the tire waste in enhancing soil performance in terms of strength, bearing capacity and permeability.

[1] Investigated the subgrade pavement soil stabilized with sliced $(10 \times 20) \mathrm{mm}$ unused tires chips. CBR tests were carried out on soil and soil-tire chips mixtures to investigate the CBR from which the adequacy of soil improved with sliced tires can be assessed. In addition to that the thickness of the pavement can also be determined from the CBR value. The founding is that the improvement in CBR of improved soil is twenty one percent in unsoaked condition and twenty two percent in soaked condition, importantly reduction in the total thickness of the pavement achieved by the increase in CBR because of that the total cost confused in the project.

[2] Study of improving shear strength of sand by mixing rubber material with fine and coarse sand in four percentages: 5, 10, 20, and 50\%. Mixing of Leighton Buzzard and Ceyhan as coarse and fine sand, respectively, with various percentages of rubber content has shown that internal friction and shear strength are reduced as the rubber content increased in the direct shear test. However, sand which includes rubber content less than $10 \%$ has yielded a maximum shear strength reduction. As the rubber content more than $10 \%$, the maximum shear strength for sand remains constant. For the angle of friction of Ceyhan sand, it is reduced up to adding $10 \%$ rubber content, while no further change occurred with the other percentages.

[3] Investigating the effect of using tire waste as an additive on bearing capacity and shear strength. To accomplish that, a many experiments have been carried out on samples of soil for different sand to tire content ratios, moisture content, and size of tire waste. Two configurations of tires waste have been applied: tire buffing and tire powder. Percentages of sand to tire mixtures of zero, Ten, Twenty and Thirty percents of waste tire content by weight were considered. Two apparatus: direct shear test device and CBR test device has been used to study the effect of tire waste material on the bearing capacity of the soil, both apparatus were calibrated and tested to meet respective standards. Results showed that adding of up to $20 \%$ of tire buffing to that sand will result in a very little effect on bearing capacity while a major effect is noticed in increasing (c and $\varnothing$ ).

\section{MATERIALS AND TESTING}

\section{Soil Properties}

A sieve analysis of used soil is carried out according to [4] is shown in Fig. 1. The used soil is indexed as SW (Wellgraded sand with gravel) accordance to the Unified 
Classification. The physical and chemical properties are density. Chemical properties include $\mathrm{SO}_{3}$ content, total drawn in Table 1. Physical properties represented by water soluble salt content (T.S.S), organic content and gypsum content, sieve analysis, specific gravity and maximum content.

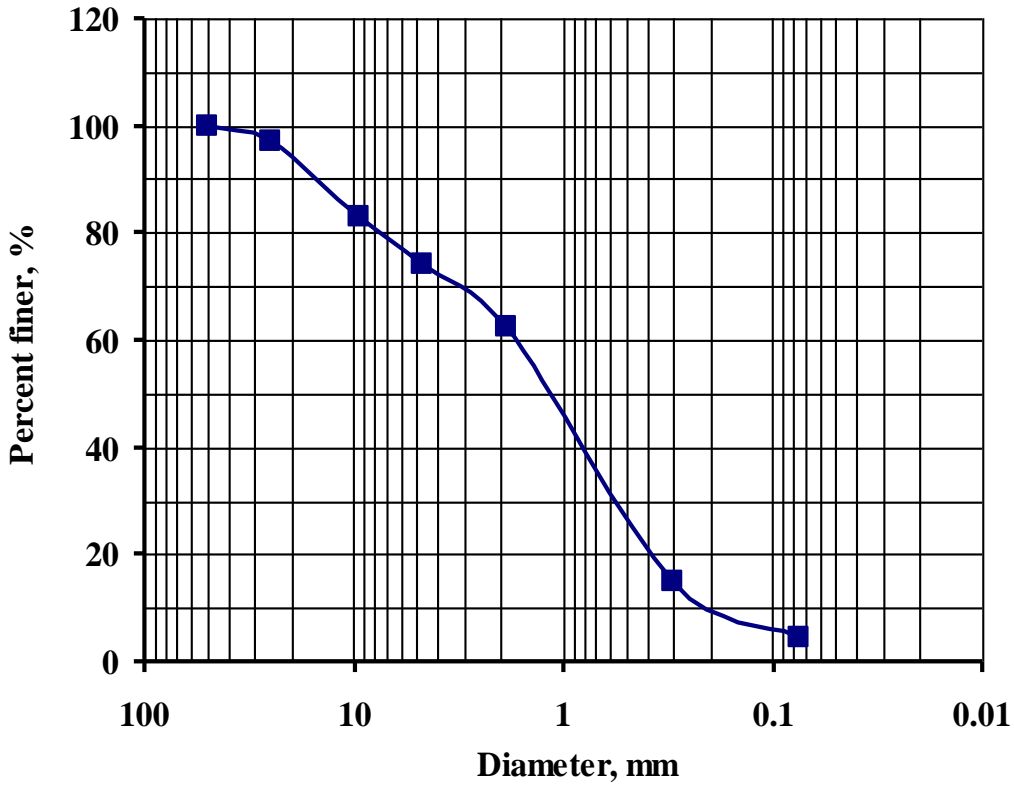

Fig.1. Grain size distribution of used soil

\section{Tires Reclaim}

case softens and inflation the rubber. The viscosity of the Remade the loss rubber is a very considerable problem. In rubber is reduced by reducing the polymer chain by theory as well as economically and actually. From the mechanical shear and chemical action.

various origins of scrap rubber, those gotten from tires are Reclaimed rubber factory is one of the factories of State the much useful. Thus, over the past few years, important Company for Tire Industry in Iraq. The reclaimed rubber care has been given to the rubber application's problem of produced by this factory, part of it used by Babylon tires disposing of this scrap. Reclaimed Rubber is cured rubber factory and the rest marketed to sister companies and the that has passed through a Thermo-Chemical process. This private sector, this Reclaim is used in this study.

Table 1 Chemical and Physical Properties of Used Soil

\begin{tabular}{|l|l|l|l|l|l|l|l|l|}
\hline \multirow{2}{*}{ The chemical Properties } & $\mathrm{So}_{3}$ & T.S.S & Organic Content & Gypsum & - & - & - & - \\
\cline { 2 - 9 } & $0.1 \%$ & $0.3 \%$ & $0.01 \%$ & $0.5 \%$ & - & - & - & - \\
\hline \multirow{2}{*}{ The physical properties } & $\mathrm{G}_{\mathrm{s}}$ & $\gamma_{\mathrm{d} \max }$ & O.M.C & $\mathrm{LL}$ & $\mathrm{PL}$ & $\mathrm{PI}$ & $\mathrm{C}_{\mathrm{u}}$ & $\mathrm{C}_{\mathrm{c}}$ \\
\cline { 2 - 9 } & 2.62 & 20.5 & $8.2 \%$ & $28 \%$ & $16 \%$ & $12 \%$ & 9.25 & 1 \\
\hline
\end{tabular}

\section{III.CBR TEST}

California Bearing Ratio (CBR) test is a laboratory test used to estimate of base, sub-base and subgrade layer strength of roads. The CBR was developed by the California Department of Transportation, and since then it has been used for pavement design purposes. It was intended to describe granular aggregates with sizes ranging between $4.75 \mathrm{~mm}$ and $20 \mathrm{~mm}$. More recently it has been used for soil materials. To simulate the effect of long - term soaking field condition, the soaked CBR is determined on a representative sample of the soil. First, compaction of each specimen and other sample of the remaining material after compaction of each specimen, the water content is determined then according to [5]. The optimum water content and maximum dry density according to the compaction method specified [6] are determined. The water content-unit weight relation for the 10-blow and 30-blow per layer compactions is made and each test specimen compacted is penetrated. water content-unit weight relation for the 65- blows is developed also to specified unit weight at or near hundred percent $\gamma_{d}$ max so it will be very important to give an offort of compaction greater than fifty six blows for each layer, [7].

All compaction is performed in the CBR mold. The relationship between load and penetration for the 4 days soaking soil can be drawn and choose corrected stress values taken from the relationship for $2.54 \mathrm{~mm}$ and 5.08 $\mathrm{mm}$ displacements, evaluate the bearing ratios of each by division the corrected stresses by the standard pressures $6900 \mathrm{kPa}$ and $10300 \mathrm{kPa}$ respectively, [7], the higher value is adopted as a CBR. The equipment of CBR test is shown in Fig. 2. 


\section{IV.RESULTS AND ANALYSIS}

Many CBR laboratory experiments on the soil samples without and with $0.5 \%, 2 \%$ and $4 \%$ Reclaim. The tests are performed under 4 days soaking condition to simulate the long-term soaking case. CBR results are recorded and the comparisons are drawn as follows:

\section{CBR Test Calculation}

According to (ASTM D854-05, 2007), the relationship between load and penetration is drawn to determine stress value corresponding to $2.54 \mathrm{~mm}$ and $5.08 \mathrm{~mm}$ penetration and estimate the bearing ratios for each by division the corrected pressures by the standard stresses of $6900 \mathrm{kPa}$ and $10300 \mathrm{kPa}$ respectively.

Figure 3 show the relationship between penetration and stress for 10,30 and 65 blows for original soil $(0 \%$ Reclaim), the value of CBR for this case is $10.8,15.7$ and 21.5 for 10,30 and 65 blows respectively. Figures 4,5 and 6 shows the same relationship for $0.5 \%, 2 \%$ and $4 \%$ Reclaim of the weight of soil, the same procedure adopted to calculate CBR.

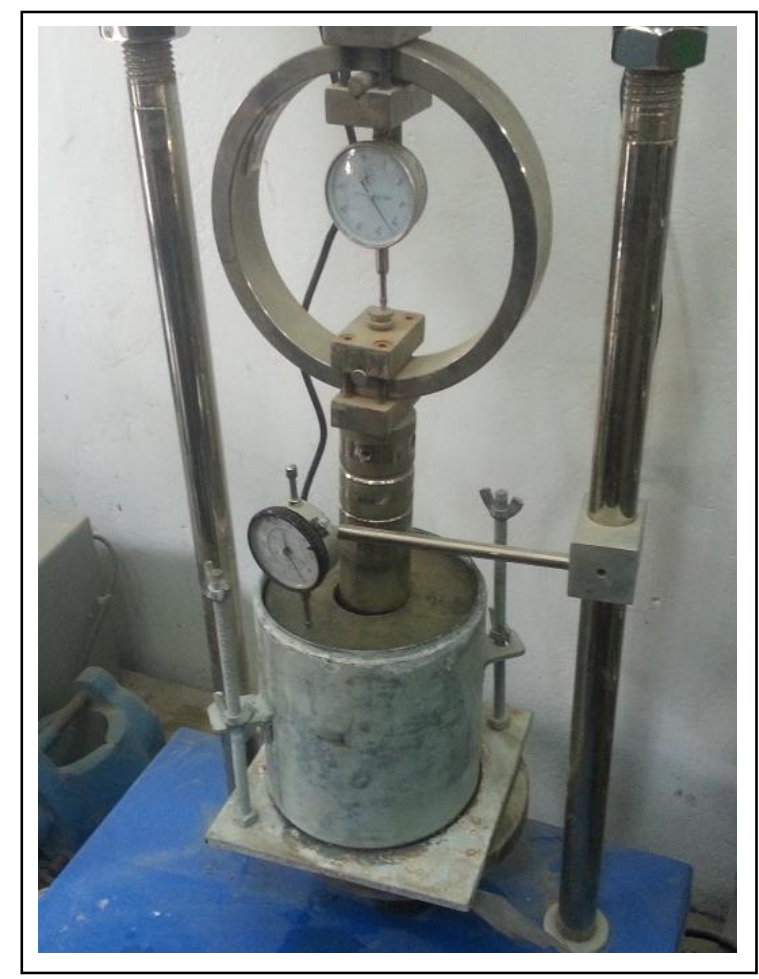

Fig 2 CBR equipment

2. Percent of Reclaim and Dry Unit Weight Fig. 9 show clearly this effect by drawing the relationship Relationship between the percent of Reclaim and CBR value. From this The water content-unit weight relation for the 10 blows, figure it can be seen that the CBR decrease by add the 30 blows and 65 blows per layer compactions is made and Reclaim to the sandy soil. To make the decrement in CBR each test specimen compacted is penetrated. The resulting from add the Reclaim to the soil more clear, the relationship between the percent of Reclaim and relationship between the percent of Reclaim and CBR maximum dry density for each No. of blows can be drawn ratio is drawn as shown in Fig. 10. as shown in Fig. 7. From this figure it can be seen that the maximum dry density increase significantly when the percent of Reclaim increase up to $1 \%$ and the increment vanishes gradually reaching to $4 \%$ Reclaim.

CBR ratio can be expressed by the following equation as:

$\mathrm{CBR} \%=\left[\left(\mathrm{CBR}_{\mathrm{w}}-\mathrm{CBR}_{\mathrm{R}}\right) /\left(\mathrm{CBR}_{\mathrm{w}}\right)\right] \times 100 \%$

\section{Dry Unit Weight and CBR Relationship}

Where,

Design CBR for one water content only using the data obtained from the 3 specimens by plotting the CBR-dry density as molded relation for 4 days as a periods of soaking as shown in Fig. 8.

\section{Effect of Reclaim on CBR}

One of the main aims of this study is investigating the effect of add the Reclaim to the sandy soil.

$\mathrm{CBR} \%=\mathrm{CBR}$ ratio
$\mathrm{CBR}_{\mathrm{w}}=\mathrm{CBR}$ without Reclaim
$\mathrm{CBR}_{\mathrm{R}}=\mathrm{CBR}$ with Reclaim

This ratio show the increment in CBR as a percentage, for example, in Fig. 10 at the percent of Reclaim $2 \%$ the increment in CBR is $21.7 \%$ 
International Advanced Research Journal in Science, Engineering and Technology Vol. 3, Issue 5, May 2016

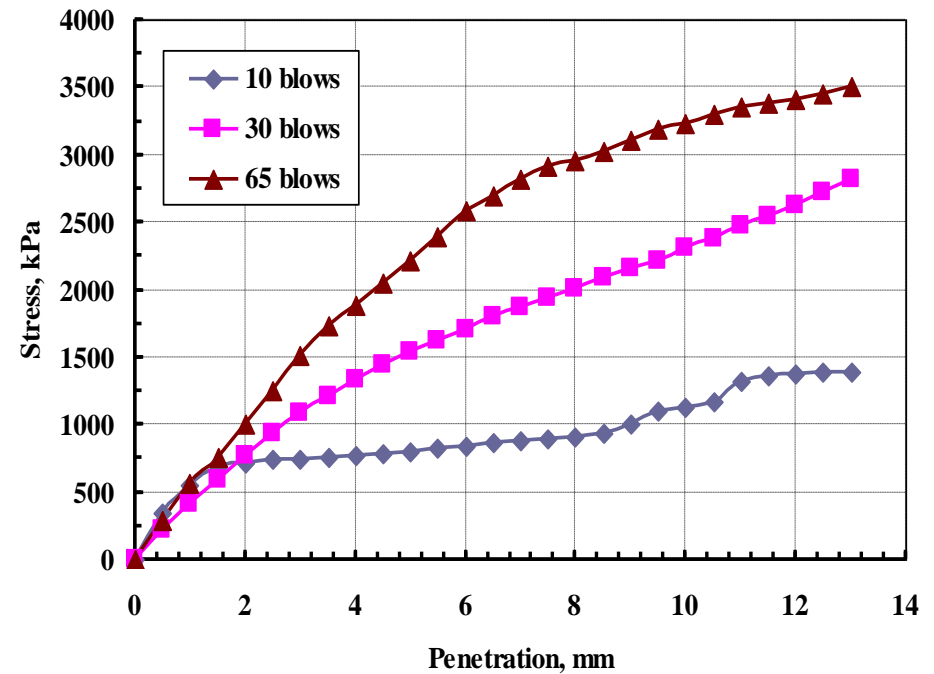

Fig. 3. Load - Penetration curves of CBR test for original soil ( $0 \%$ Reclaim) case

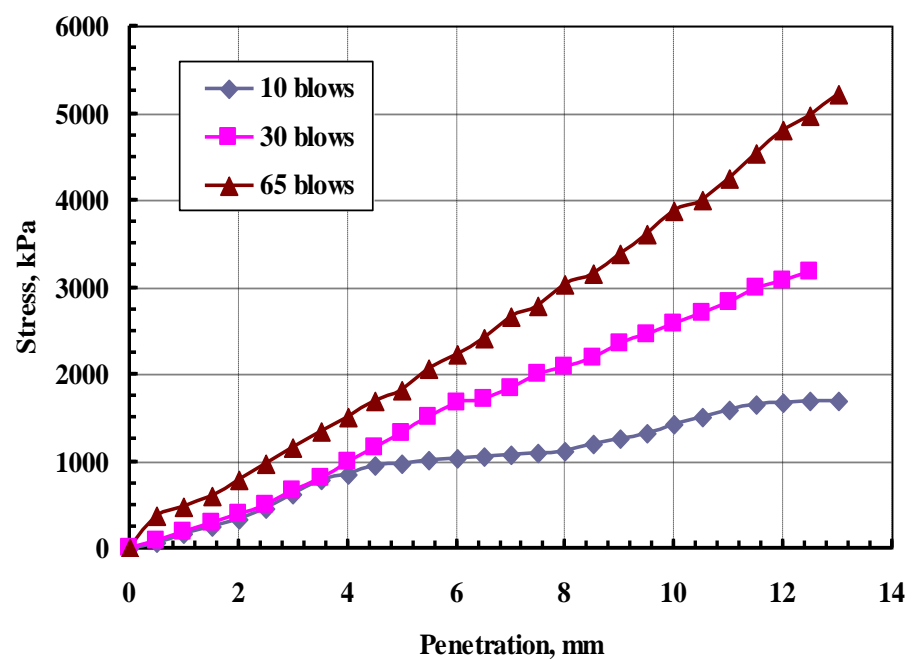

Fig. 4. Load - Penetration curves of CBR test for $0.5 \%$ Reclaim case

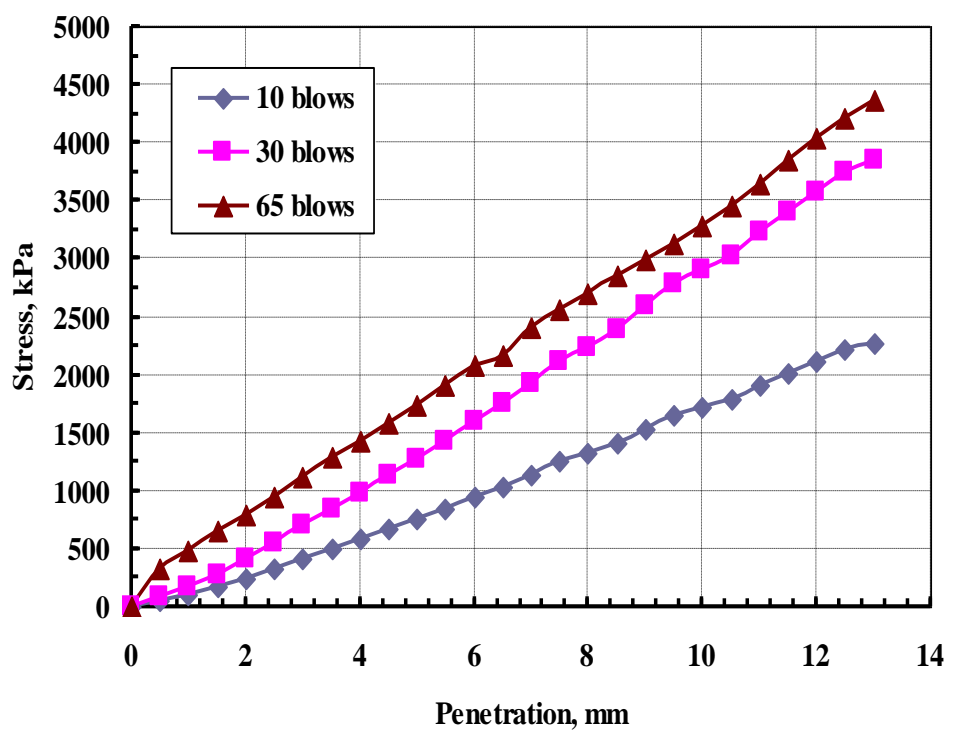

Fig. 5. Load - Penetration curves of CBR test for 2\% Reclaim case 
IARJSET

International Advanced Research Journal in Science, Engineering and Technology Vol. 3, Issue 5, May 2016

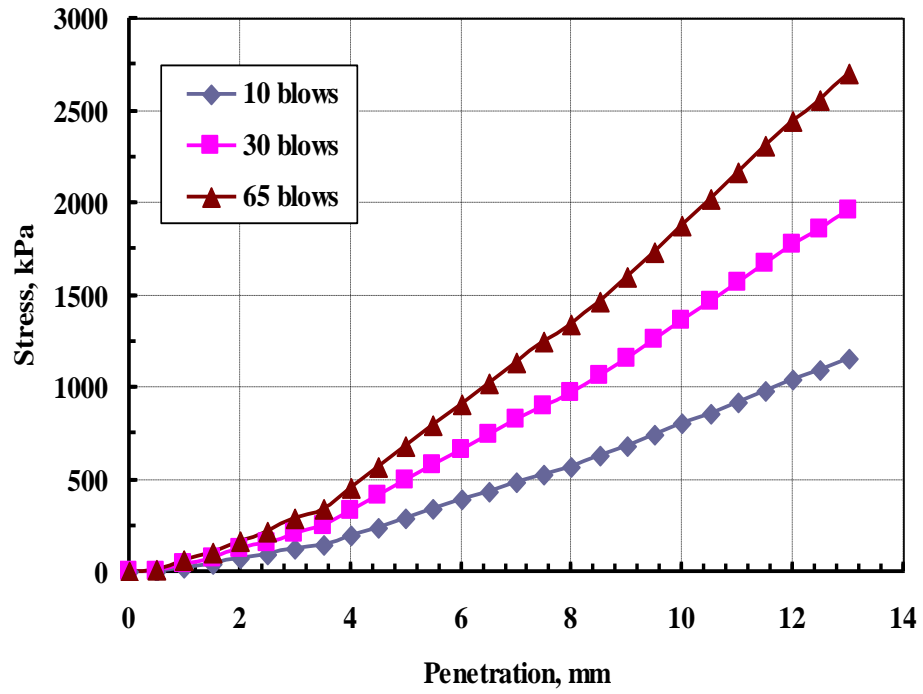

Fig. 6. Load - Penetration curves of CBR test for 4\% Reclaim case

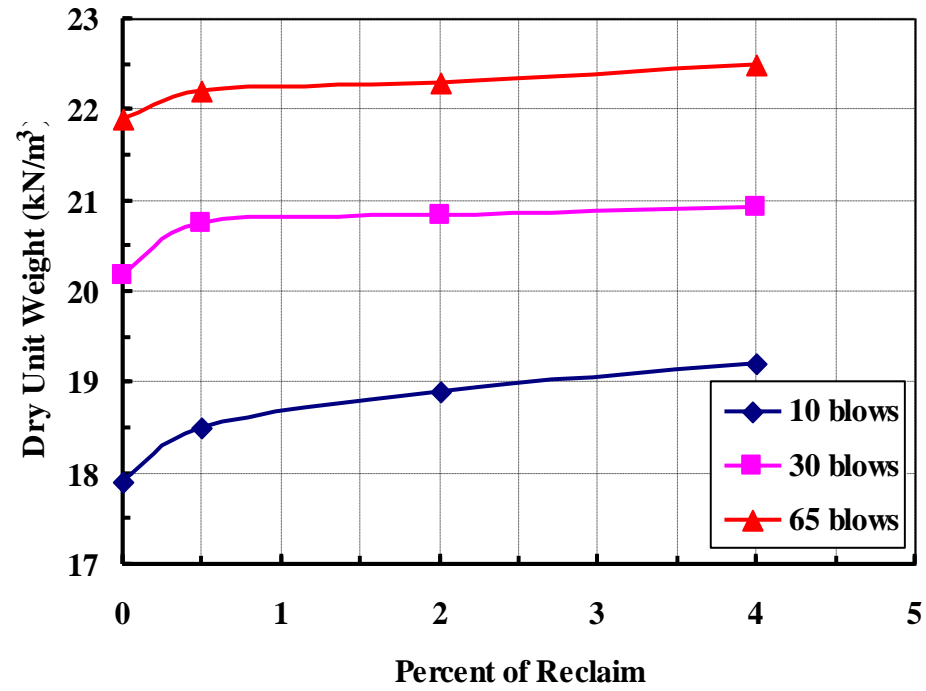

Fig.7. Percent of Reclaim and unit weight relationship

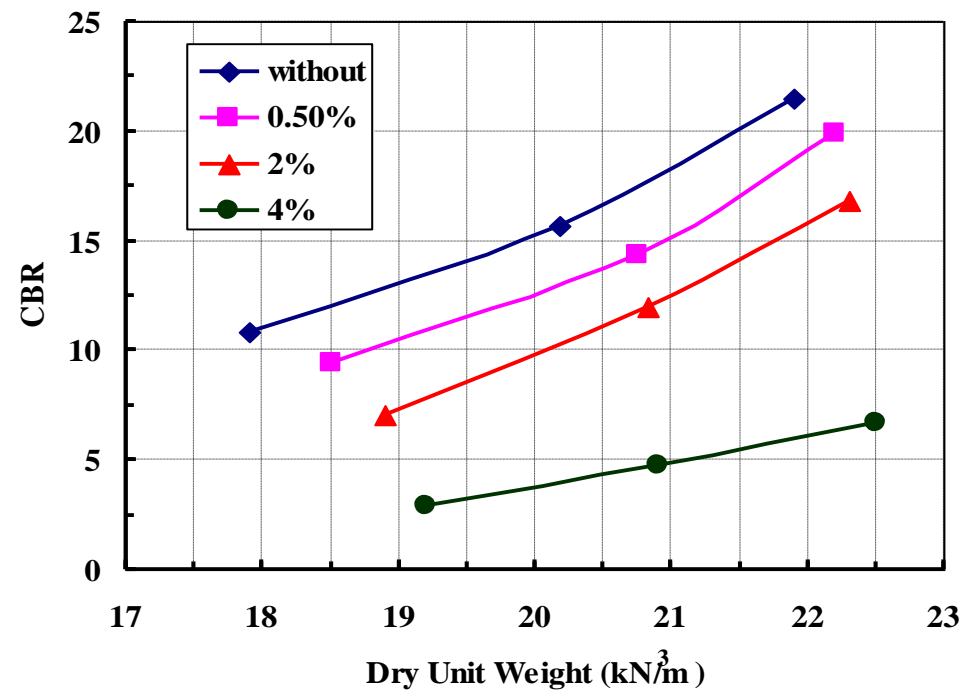

Fig. 8. Dry unit weight and CBR relationship 
International Advanced Research Journal in Science, Engineering and Technology

Vol. 3, Issue 5, May 2016

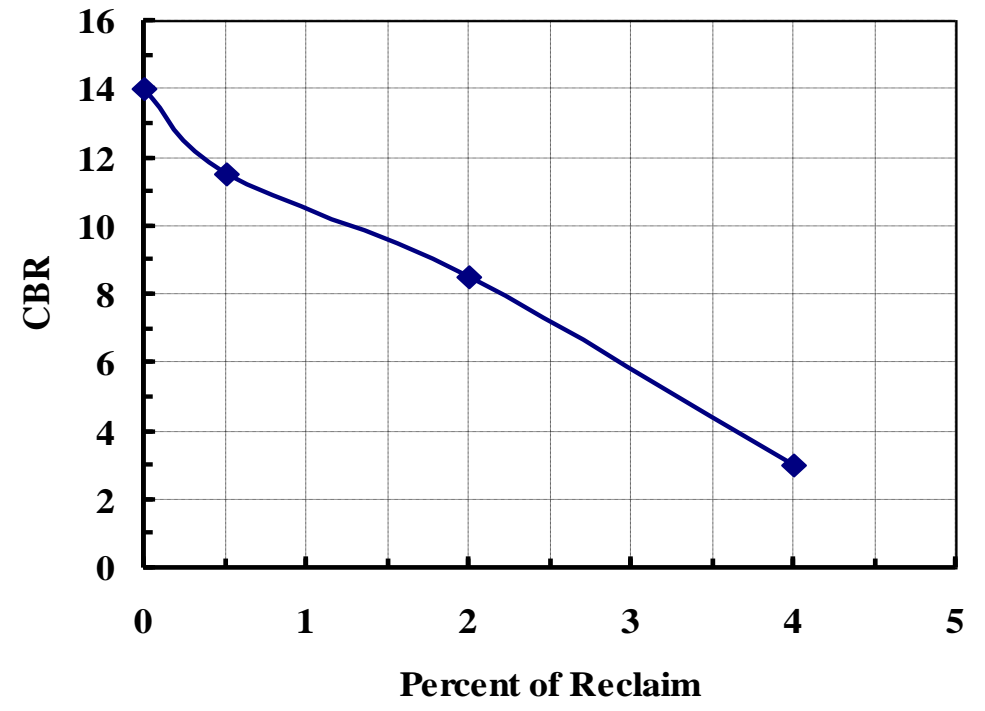

Fig. 9. Percent of Reclaim and CBR relationship

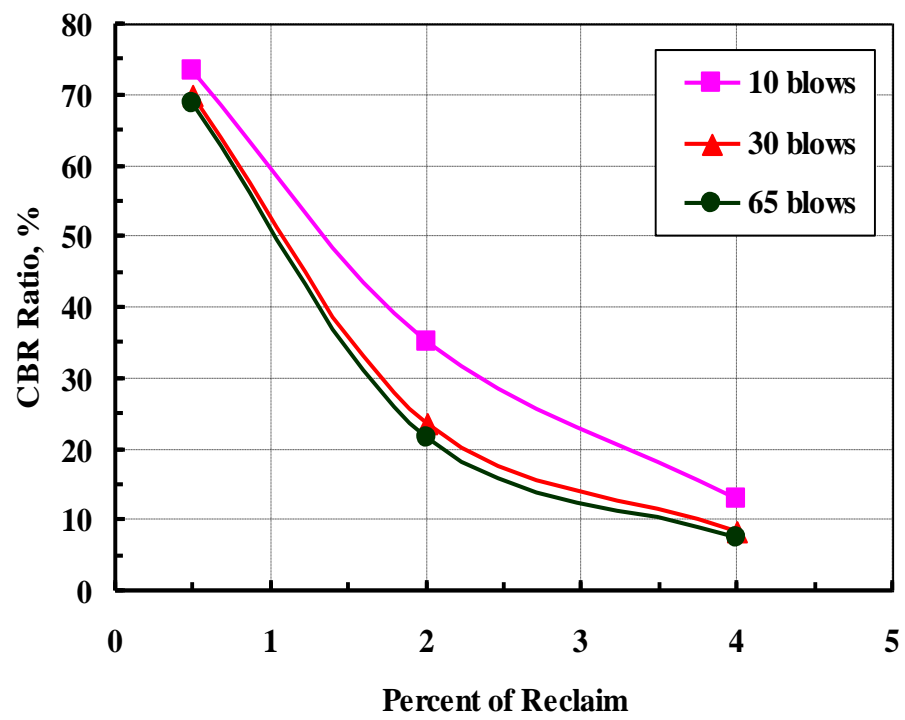

Fig. 10. Percent of Reclaim and CBR ratio relationship

\section{CONCLUSIONS}

Many laboratory tests on soil samples to find the value of CBR without and with Reclaim $(0.5 \%, 2 \%$ and $4 \%$ Reclaim by the weight of soil). The tests are performed under 4 days soaking condition to simulate the long-term soaking case. Many conclusions can be drawn as:

1- The dry unit weight of sandy soil increase when the prcent of Reclaim increase, the increase is significant up to $2 \%$ Reclaim and the increment decrease gradually up to $4 \%$ Reclaim.

2- For all cases $(0 \%, 0.5 \%, 2 \%$ and $4 \%)$ Reclaim, CBR increase as the dry unit weight increase for each case separately.

3- California Bearing Ratio (CBR) decrease when the percent of Reclaim increase, thus, use of Reclaim do not improve the soil to bear the applied loads.

4- The increment in CBR varies from $7.6 \%$ to $68.8 \%$ when the percentage of Reclaim varies from $0.5 \%$ to $4 \%$.

\section{REFERENCES}

[1] R. Ayothiraman and Ablish Kumar Meena, 2011, "Improvement of Subgrade Soil with Shredded Waste Tire Chips", Proceedings of Indian Geotechnical Conference, pp. 365-368.

[2] Cabalar, A. F., 2011, "Direct Shear Tests on Waste Tires-Sand Mixtures", Geotechnical and Geological Engineering, pp. 1-8.

[3] Hamidreza Pourfarid, 2013, "The Potential of Using Waste Tire as a Soil Stabilizer," MSc. Eng., thesis. Eastern Mediterranean University, Cyprus.

[4] ASTM D422-63, 2007, "Standard Test Method for Particle SizeAnalysis of Soils".

[5] ASTM D2216-98, (2007), "Laboratory Determination of Water (Moisture) Content of Soil and Rock by Mass".

[6] ASTM D1557, (2007), "Laboratory Compaction Characteristics of Soil Using Modified Effort".

[7] ASTM D854-05, (2007), "Standard Test Method for California Bearing Ratio of Laboratory-Compacted Soils". 